\title{
Bioprospection of bacteria and yeasts from Atlantic Rainforest soil capable of growing in crude-glycerol residues
}

\author{
E.A.A. Duarte ${ }^{1}$, G.V. Lacerda Jr ${ }^{1}$, T.A.S. de Oliveira $^{2}$, M. Brendel ${ }^{1}$, \\ L.L. Loguercio ${ }^{1}$, J.C. de M. Cascardo ${ }^{1 \dagger}$ \\ ${ }^{1}$ Centro de Biotecnologia e Genética, Universidade Estadual de Santa Cruz, \\ Ilhéus, BA, Brasil \\ ${ }^{2}$ Laboratório de Expressão Gênica, Universidade Federal Rural de Pernambuco, \\ Recife, PE, Brasil
}

Corresponding author: L.L. Loguercio

E-mail: leandro@uesc.br

Genet. Mol. Res. 12 (4): 4422-4433 (2013)

Received February 14, 2013

Accepted August 27, 2013

Published October 10, 2013

DOI http://dx.doi.org/10.4238/2013.October.10.8

\begin{abstract}
The increasing world production of biodiesel has resulted in an accumulation of crude glycerol as the major byproduct. This could be used as carbon source for industrial microbiology, with economic and environmental advantages for the biodiesel industry. We explored an Atlantic Rainforest soil sample to search for crude glycerol-degrading microorganisms. Microcosms of this soil were established containing minimal medium $+8 \%$ crude glycerol $(\mathrm{w} / \mathrm{w})$; the biological activity was measured by respirometry. High $\mathrm{CO}_{2}$ levels were found in some of the crude glycerol microcosms, suggesting the activity of microorganisms capable of degrading this residue. In an attempt to isolate and cultivate these microorganisms in vitro, aliquots of the soil suspension were plated on minimal medium containing 10\% crude glycerol (v/v). Out of 19 morphologically distinct isolates, 12 bacteria and 6 yeasts were identified by PCR from universal primers $16 \mathrm{~S}$ and $26 \mathrm{~S}$ rDNA, respectively. Optical density readings revealed growth differences among cultures.
\end{abstract}


Two yeasts and three bacteria with distinct growth profiles stood out and appeared to have potential for liquid fermentation of crude glycerol. The yeasts adapted rapidly, but produced relatively little biomass. Opposite tendencies were found in the bacteria. Amplicon sequencing placed the bacterial isolates as close to Staphylococcus arlettae, Pseudomonas citronellolis, and Bacillus megaterium, and the yeasts to Trichosporon moniliiforme and Meyerozyma guilliermondii. We concluded that these species have potential for use in crude glycerol bioreactors and for bioremediation processes.

Key words: Biofuels; Glycerol conversion; Microbial diversity; Clean energy; Crude glycerin; Glycerol industry

\section{INTRODUCTION}

The world market of "green/clean" energy is increasingly counting on biodiesel as a viable alternative to fossil fuels for environmentally sustainable development (Dobson et al., 2012; Yang et al., 2012). However, around $10 \%$ of the biodiesel production results in crude glycerol as the main by-product of this process (da Silva et al., 2009). Therefore, the increased worldwide production of this fuel in recent years has brought a much larger availability of crude glycerol for this specific market, with a concomitant drop in its prices (Yazdani and Gonzalez, 2007). This residue is usually qualitatively and quantitatively contaminated by various other substances that participate in, or are derived from, biodiesel production; they vary according to i) the biological origin of the oils and fats used as raw material, ii) the catalyst type and efficiency of the transesterification process, iii) the biodiesel yields, iv) the initial levels of present impurities, and v) whether there is any sort of recovery for the catalyst and methanol employed (Thompson and He, 2006; Yang et al., 2012). Such variation and the chemical nature of these contaminants make the direct use of crude glycerol unviable for food, pharmaceutical, chemical, and synthetic material industries (Ashby et al., 2011), which commonly use pure glycerol. Thus, the use of crude glycerol in other applications and/or in its bioconversion to other products with economic value appear to be the best alternative for its processing in biodiesel production facilities (Johnson and Taconi, 2007; Min et al., 2010; Dobson et al., 2012).

To process the crude glycerol residue based upon economic and environmentally sustainable methods that lead to value-added products, several approaches have been developed (e.g., Mu et al., 2008; Min et al., 2010; Posada et al., 2011; Ashby et al., 2011; Varrone et al., 2012). As noticed from these studies, the use of microorganisms capable of degrading/converting crude glycerol has been a major strategy proposed (Pagliaro et al., 2007). The predominant type of work reported in recent years employs pre-selected and/or already established strains of microorganisms for glycerol-bioconversion processes (Mu et al., 2008; Rymowicz et al., 2010; Gungormusler et al., 2011; Ashby et al., 2011), which is relevant in view of the urge of developing biotechnologies able to efficiently cope with the waste of biodiesel production (Yazdani and Gonzalez, 2007; Dobson et al., 2012). However, the screening for new strains of microorganisms showing greater or more rapid degradation of crude glycerol, or even displaying novel metabolic features in terms of value-added compounds they can generate directly from growth on this residue, should not be relegated in this context. New crude glycerol-degrading isolates 
can be used either alone or making up microbial consortia, which are showing to be very promising for this purpose (Gallego et al., 2007; Varrone et al., 2012). Not unexpectedly, the tendency in screening studies of this nature is to seek novel isolates exactly in those environments enriched with the same target substrate (e.g., Maciel et al., 2007; Franciscon et al., 2009), due to the higher possibility of finding microorganisms already adapted to these human-generated ecological niches. Nevertheless, other sources of diverse microbes should not be neglected, since glycerol is an abundant carbon source in nature (it is a structural component of many lipids), and so, likely prone to be metabolized by a great variety of microorganisms.

From the point of view of biotechnology, bacteria and yeasts are important groups because their representatives in terrestrial microbiota are recognized by the high species diversity, adaptive plasticity, and metabolic versatility, which allow their employment in numerous biodegradation processes (e.g., Maciel et al., 2007; Milić et al., 2009; Franciscon et al., 2009). The microbial biodiversity of soils from the Atlantic Rainforest is expectedly very large, due to a higher diversity of plants (Myers et al., 2000; Arnold et al., 2002) and to a much lower anthropic disturbance of this environment (Hanada et al., 2010). Hence, an interesting hypothesis to be tested is whether a supposedly largely diverse ecosystem can harbor microbial species able to degrade human-generated compounds, even when no previous contact with such compound has occurred.

The process of biodegradation of organic compounds in soil can be assessed by microbial respiration, by measuring the emission of $\mathrm{CO}_{2}$ and/or uptake of $\mathrm{O}_{2}$, which indicate the presence of biological activity (Marin et al., 2005). In this context, the Bartha respirometer (Bartha and Pramer, 1965) is a simple method that is frequently used in measurements of microbial activity in soil microcosms (ABNT, 1999; Mello et al., 2007). In addition, once the existence of active microbes in a given environment is established, subsequent biotechnological applications depend on the possibility of isolating and cultivating these microorganisms in vitro. Hence, the objectives of this study were i) to determine the biological activity in microcosms of an Atlantic Rainforest soil sample (from a biodiversity 'hot-spot' area) that was enriched with crude glycerol, ii) to test the possibility of isolating microorganisms that are crude glycerol-degraders, with distinct patterns of growth, and cultivating them in vitro, and iii) to characterize these isolates taxonomically by DNA sequencing, to identify bacteria and yeasts with potential applicability in biodegradation/ bioconversion of crude glycerol.

\section{MATERIAL AND METHODS}

\section{Soil samples}

Soil samples were collected at a site in the Atlantic Rainforest, located at $14^{\circ} 47^{\prime} 6^{\prime \prime} \mathrm{S}$ and $39^{\circ} 13^{\prime} 25^{\prime \prime} \mathrm{W}$ in the city of Ilhéus, Bahia, Brazil. In each sample, $500 \mathrm{~g}$ soil were collected at a depth of 0-20 cm, where $100 \mathrm{~g}$ were obtained from each of five collection spots, spaced 5 $\mathrm{m}$ apart. The samples were sieved in a $2-\mathrm{mm}$ mesh, packed in plastic bags and stored at $4^{\circ} \mathrm{C}$ for further analysis.

\section{Soil microcosms enriched with crude glycerol and respirometric studies}

The crude glycerol used in the experiments was the residue obtained by the trans- 
esterification of Jatropha oil (Jatropha curcas L.) used for biodiesel production and kindly provided by the group of Bioenergy and Environment of the State University of Santa Cruz (Ilhéus, BA, Brazil). The 'microcosms' formed from Atlantic Rainforest soil consisted of $50 \mathrm{~g}$ soil, $15 \mathrm{~mL}$ minimal medium $\left(0.1 \% \mathrm{KH}_{2} \mathrm{PO}_{4}, 0.1 \% \mathrm{~K}_{2} \mathrm{HPO}_{4}, 0.1 \% \mathrm{NH}_{4} \mathrm{NO}_{3}, 0.05 \%\right.$ $\left.\mathrm{MgSO}_{4}, 0.001 \% \mathrm{Fe}_{2} \mathrm{SO}_{4}, 0.001 \% \mathrm{CaCl}_{2}\right)$ and $5.0 \mathrm{~mL}$ crude glycerol as carbon source $(8 \%$ $\mathrm{v} / \mathrm{w})$. The control was similarly established but without addition of crude glycerol. Higher concentrations of crude glycerol (50,70 and 100\%) were also tested, but were discarded due to the high viscosity, which generated spongy and saponified compounds that impaired subsequent analyses.

The $\mathrm{CO}_{2}$ emission in these microcosms was monitored by the Bartha method used in respirometric studies, as defined in the technical standards L 6350 CETESB and NBR 14283 (ABNT, 1999). The experiment was done with triplicate measurements for each time point. Each respirometer contained a single microcosm treatment as described above. To determine the amount of $\mathrm{CO}_{2}$ possibly produced by microorganisms during aerobic metabolism of the carbon source added, $10 \mathrm{~mL} 0.2 \mathrm{~N} \mathrm{KOH}$ were added every $24 \mathrm{~h}$ for 80 days. The amount of carbon dioxide that was released by the microcosm and absorbed by this alkaline solution was estimated by titration of residual $\mathrm{KOH}$ after addition of $1 \mathrm{~mL} 1.0 \mathrm{M}$ barium chloride. A standardized solution of $0.1 \mathrm{~N} \mathrm{HCl}$ was used to titrate $\mathrm{KOH}$. From the volume of acid added during titration, the release of $\mathrm{CO}_{2}$ was quantified using the formula:

$$
\left[\mathrm{CO}_{2}\right]=(\mathrm{A}-\mathrm{B}) 50 \mathrm{f}_{\mathrm{HCl}},(1)
$$

where: $\mathrm{A}=$ volume of $0.1 \mathrm{~N} \mathrm{HCl}$ used to titrate the $\mathrm{KOH}$ solution in the blank test $(\mathrm{mL})$; $\mathrm{B}$ $=$ volume of $0.1 \mathrm{~N} \mathrm{HCl}$ used to titrate the $\mathrm{KOH}$ solution in each treatment $(\mathrm{mL}) ; 50=$ factor to convert the volume of $\mathrm{CO}_{2}$ to micromoles $(\mu \mathrm{mol}) ; \mathrm{f}_{\mathrm{HCl}}=$ factor of the $0.1 \mathrm{~N} \mathrm{HCl}$ solution (Mello et al., 2007).

\section{Isolation of microorganisms in media containing crude glycerol}

Different proportions of soil, minimal medium and crude glycerol from those described above were used to make a suspension that could enable better manipulation and potential isolation of microorganisms capable of metabolizing the crude glycerol. In $250 \mathrm{~mL}$ minimal medium (in a $500 \mathrm{~mL}$ Erlenmeyer flasks), $25 \mathrm{~g}$ crude glycerol $+200 \mathrm{~g}$ soil were added and maintained under constant stirring at $120 \mathrm{rpm}$, at a temperature of $25^{\circ} \pm 2^{\circ} \mathrm{C}$. The bottle was sealed, but allowed aeration; it was incubated for 90 days, seeking to reproduce roughly the period of enrichment with crude glycerol of the soil sample in the respirometer (see above). After this incubation period, aliquots were removed for in vitro culture.

In a Petri dish $(100 \times 20 \mathrm{~mm})$ containing minimal medium (see composition above), $1.5 \%$ agar and $10 \%$ crude glycerol $(\mathrm{v} / \mathrm{v}), 100 \mu \mathrm{L}$ soil suspension enriched with crude glycerol (after 90 days incubation) were added. For this experiment, three plates were inoculated and incubated for 7 days in a BOD incubator at $35^{\circ} \pm 2^{\circ} \mathrm{C}$. The microorganisms that grew in this medium were evaluated and characterized by morphology and by the Gram test. By means of subcultures in Petri dishes containing the same medium, 19 morphologically distinct microorganisms were isolated, of which 12 were bacteria and seven yeast. These isolates were stored in liquid minimal medium + pure glycerol $(25 \%, v / v)$ at $-80^{\circ} \mathrm{C}$ for later use. 


\section{Isolate identification by PCR of rRNA genes}

The isolates were subjected to PCR amplification with universal primers designed for the 16S rRNA gene of the bacterial domain, designated as 27F (5'-AGAGTTTGATCMTGGC TCAG-3') and 1525R (5'-AAGGAGGTGWTCCARCC-3') (Lane, 1991), and D1/D2 primers for the 26S subunit of rRNA gene of yeast, designated as NL-1 (5'-GCATATCAATAAGCGGA GGAAAAG-3') and NL-4 (5'-GTCCGTGTTTCAAGACGG-3') (O'Donnell, 1993). For both amplifications, the following reagents and concentrations were used: a small amount of a colony from each strain grown on the plate (DNA), 1X Taq DNA polymerase buffer, $3.7 \mathrm{mM}$ $\mathrm{MgCl}_{2}, 0.6 \mu \mathrm{M}$ dNTPs, $0.4 \mu \mathrm{M}$ each primer, $0.4 \mathrm{mM}$ bovine serum albumin (BSA), and $5 \mathrm{U}$ Taq DNA polymerase, in a final volume of $50 \mu \mathrm{L}$, adjusted with sterile ultrapure water. In these experiments, $10 \mathrm{ng}$ DNA from Escherichia coli or Saccharomyces cerevisiae were included as positive controls for bacteria and yeast, respectively. Amplified products were separated on a $1 \%$ agarose gel, stained with ethidium bromide and visualized with UV light. The amplicons were sequenced by Molecular Analysis ACTGene Ltda (Porto Alegre, RS) using the automated sequencer ABI-PRISM ${ }^{\circledR} 3100$ Genetic Analyzer (Applied Biosystems). The taxonomic identity of the isolates was assessed through Blast $N$ search in GenBank, using the general database for 26S rRNA-amplified sequences and the 16S rRNA database for the bacterial amplicons.

\section{Growth curves of isolates in liquid medium containing crude glycerol}

For standardization of inocula, the strains of bacteria were grown in nutrient agar medium at $35^{\circ} \mathrm{C}$ for $48 \mathrm{~h}$ and monitored every $12 \mathrm{~h}$. Sabouraud agar medium was used for yeasts, with the corresponding isolates incubated at $29^{\circ} \mathrm{C}$ for $24 \mathrm{~h}$. The respective inocula for bacteria and yeast were standardized in sterile saline to $0.45 \%$. To determine the growth curve of these isolates, suspensions were made at a concentration of $5 \times 10^{8} \mathrm{CFU} / \mathrm{mL}$ as the initial inoculum, which corresponded to an optical density of 0.3 on the McFarland scale. The growth curve was determined using 50-mL sterile Falcon tubes containing $20 \mathrm{~mL}$ minimal medium (see above) $+10 \%$ crude glycerol $(\mathrm{v} / \mathrm{v})$ as the sole carbon source. The flasks were incubated at $30^{\circ} \mathrm{C}$ at $120 \mathrm{rpm}$ for 7 days in an orbital shaker, with growth monitored every $24 \mathrm{~h}$ by spectrophotometry (SpectraMax Plus ${ }^{\circledR}$ ) at $600 \mathrm{~nm}$. For each isolate, three inoculations (replicates) were established in separate flasks and incubated under the same growth conditions. The growth of microorganisms in culture medium containing crude glycerol was evaluated from the optical densities (OD) at $600 \mathrm{~nm}$, with a reading every $24 \mathrm{~h}$ until the maximum time of $168 \mathrm{~h}$. The OD data obtained for each time and for each microorganism were statistically compared to identify the moments of their respective growth curves in which the increase in cell number was significant. For analysis of variance, these data were submitted to the Scott-Knott test $(\mathrm{P} \leq$ 0.05) using the SISVAR 5.3 program (Ferreira, 2011). Only significant differences in the OD values at adjacent time points are indicated by letters in Table 1 .

\section{RESULTS}

The magnitude of detectable biological activity in soil of the tropical Atlantic Rainforest enriched with $8 \%$ crude glycerol was determined by monitoring the release of $\mathrm{CO}_{2}$ in this system by respirometry (Bartha method). Over 80 days of analysis, the results clearly demon- 
strated that this method was sufficient to detect biological activity in the soil microcosm induced by crude glycerol (Figure 1). Compared with the control microcosm, a greater release of $\mathrm{CO}_{2}$ was observed in the glycerol-containing microcosm as early as the 5th day. For this treatment, $\mathrm{CO}_{2}$ production varied between 125 and $300 \mu \mathrm{mol}$ starting on the 10th day of analysis, with maximum emission between 55 and 65 days of incubation. As it might be expected, the control treatment that consisted only of original soil + minimal medium without added carbon source, showed some production of $\mathrm{CO}_{2}(90 \mu \mathrm{mol})$ only in the initial phase of the observations, with a sharp decline in the amounts of this gas released in the final period of the experiment (Figure 1).

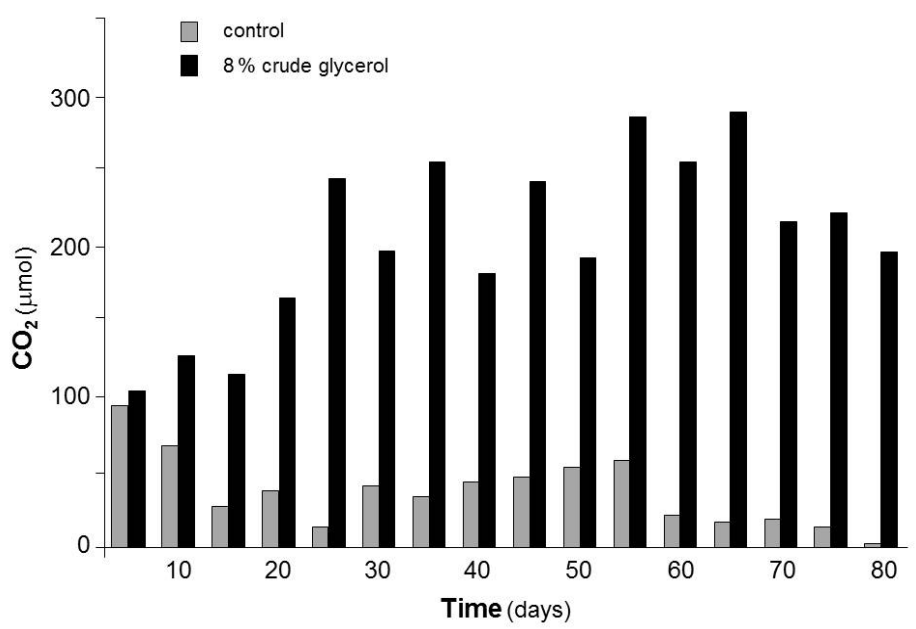

Figure 1. Production of $\mathrm{CO}_{2}$ in tropical Atlantic Rainforest soil evaluated by the method of Bartha. Values in the graph are mean of three replicates. Control = control microcosm, only with soil + minimal medium (gray bars); $8 \%$ : control microcosm plus the addition of this percentage of crude glycerol (black bars).

To examine the possibility of identifying cultivable microorganisms from the Atlantic Rainforest soil with potential to consume crude glycerol, we established a soil suspension in minimal medium containing this residue. After 90 days of incubation, aliquots of this suspension were plated and incubated in minimal medium containing $10 \%$ crude glycerol. Several morphologically distinct colonies were observed on the plates after $24 \mathrm{~h}$ incubation at $28^{\circ}$, $32^{\circ}$, and $35^{\circ} \mathrm{C}$, respectively (data not shown). In proceeding with molecular characterization, 19 isolates with distinct morphological features were selected for PCR amplification with universal primers for the 16S rRNA gene of bacteria and the 26S rRNA gene of yeast (Figure 1). The results for the 19 isolates under study confirmed that they are members of these two taxonomic groups (Figure 2). The amplification was positive for all 12 strains of bacteria and for six of the seven yeast isolates (Figure 2). Interestingly, the results for yeast amplification revealed the presence of two bands around the expected size ( $\sim 650 \mathrm{bp})$ but differing slightly. Only the larger fragment was observed for three isolates, only the smaller for two isolates, and both fragment sizes at the same time for one of the isolates (Figure 2B).

The use of microorganisms in biotechnology relies on the knowledge of their growth pattern in liquid medium, considering the cost/benefit ratio for large-scale production, especially in liquid fermentation. Aiming at further studies, a preliminary analysis of the growth profiles in culture for the 19 isolates under study (data not shown) allowed the selection of five (three 
bacteria and two yeasts) that showed distinct growth patterns. Statistically significant differences among mean OD values at $600 \mathrm{~nm}$, per time point for each isolate, were used as an indicator of those moments when there were significant increases in growth rates for each culture (inflection points on the respective curves; Table 1). The A1 and E2 strains reached log phase during the first 24 to $48 \mathrm{~h}$ of growth, showing more rapid adaptation responses in culture medium containing crude glycerol. However, their optical density values at later times showed stabilization at lower levels of cell biomass. In contrast, $\mathrm{H} 1$ and $\mathrm{C}$ isolates took a longer time to reach the exponential phase of growth (between 72 and $96 \mathrm{~h}$ ), but the final cell biomass in each culture was higher. Finally, the H2 strain showed two moments of inflection in its growth curve (Table 1).

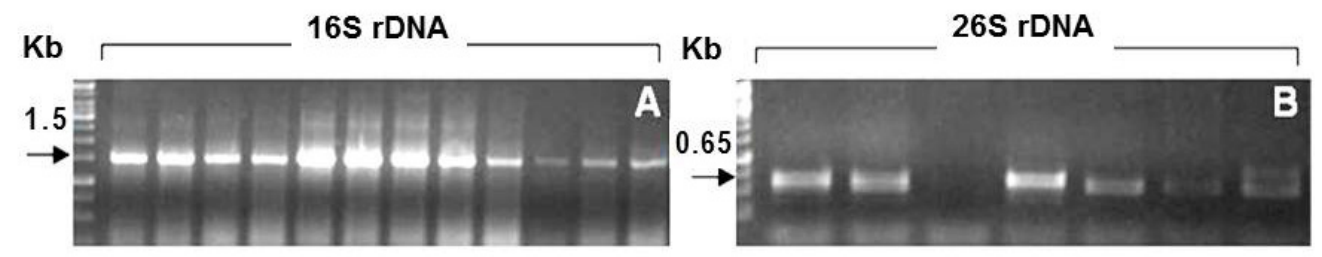

Figure 2. Characterization by PCR of 19 microbial isolates cultivated in vitro on medium containing $10 \%(\mathrm{v} / \mathrm{v})$ crude glycerol. Electrophoresis on $1 \%$ agarose gel. Amplification results for bacterial $16 \mathrm{~S}$ rDNA (A) and yeast $26 \mathrm{~S}$ rDNA (B) universal primers. Expected molecular weights for the respective fragments are indicated by arrows.

\begin{tabular}{|c|c|c|c|c|c|c|c|c|}
\hline \multirow[t]{2}{*}{ Isolate $^{1}$} & \multicolumn{7}{|c|}{ OD at $600 \mathrm{~nm}^{2}$} & \multirow[b]{2}{*}{$168 \mathrm{~h}$} \\
\hline & $0 \mathrm{~h}$ & $24 \mathrm{~h}$ & $48 \mathrm{~h}$ & $72 \mathrm{~h}$ & $96 \mathrm{~h}$ & $120 \mathrm{~h}$ & $144 \mathrm{~h}$ & \\
\hline$\overline{\mathrm{C}}$ & 0.0 & 0.18 & 0.25 & $0.23^{\mathrm{a}}$ & $0.82^{\mathrm{b}}$ & 0.95 & 1.02 & 0.93 \\
\hline H1 & 0.0 & 0.09 & 0.13 & $0.12^{\mathrm{a}}$ & $0.80^{\mathrm{b}}$ & 1.01 & 1.20 & 0.96 \\
\hline $\mathrm{H} 2$ & $0.0^{\mathrm{a}}$ & $0.42^{\mathrm{b}}$ & 0.34 & $0.33^{\mathrm{b}}$ & $0.55^{\mathrm{c}}$ & 0.76 & 0.79 & 0.74 \\
\hline $\mathrm{A} 1$ & $0.0^{\mathrm{a}}$ & $0.34^{\mathrm{b}}$ & 0.55 & 0.47 & 0.43 & 0.51 & 0.58 & 0.52 \\
\hline E2 & 0.0 & $0.17^{\mathrm{a}}$ & $0.36^{\mathrm{b}}$ & 0.34 & 0.37 & 0.42 & 0.45 & 0.37 \\
\hline CV (\%) & 14.95 & & & & & & & \\
\hline
\end{tabular}

${ }^{1}$ Isolates $\mathrm{C}, \mathrm{H} 1$, and $\mathrm{H} 2$ = bacteria; $\mathrm{A} 1$ and $\mathrm{E} 2$ = yeast. ${ }^{2}$ Values in each row followed by different letters are statistically different, according to the Scott-Knott test $(\mathrm{P}<0.05)$, indicating points of the curve where steeper growth was observed. Values before and after those with significance letters were not statistically different from previous and subsequent ones (letters were removed for clarity).

rRNA sequences obtained from these five microorganisms were compared with other sequences in the NCBI database using the BlastN program. To define the taxon corresponding to our isolates, the highest scores in the output table of aligned sequences were considered priority for the identification, when the other parameters showed the same value among accessions. With this criterion, all five sequences allowed the identification of our isolates to the species level, showing a percentage of identity $>94 \%$ and a sequence coverage $>98 \%$ (Table 2). Interestingly, the fragment amplified and sequenced for the $\mathrm{H} 1$ strain, which was identified as Pseudomonas citronellolis, showed 18 extra nucleotides along the region of coverage (477 bases from a total of 479 - Table 2) compared to the sequences in the database that aligned with it (data not shown). 
Table 2. Identification of the five microorganisms isolated in vitro on medium supplemented with $10 \%$ crude glycerol.

\begin{tabular}{|c|c|c|c|c|c|}
\hline Isolate & Query size $(b p)^{1}$ & Query coverage (\%) & Nucleotide identity $(\%)^{2}$ & Taxon & Accession No. ${ }^{3}$ \\
\hline \multicolumn{6}{|c|}{ Bacteria } \\
\hline $\mathrm{C}$ & 353 & 99 & 96 & Staphylococcus arlettae & JX188021 \\
\hline H1 & 479 & 99 & 94 & Pseudomonas citronellolis & AB021396 \\
\hline $\mathrm{H} 2$ & 618 & 98 & 99 & Bacillus megaterium & JN845569 \\
\hline \multicolumn{6}{|l|}{ Yeast } \\
\hline A1 & 357 & 99 & 99 & Trichosporon moniliiforme & GQ367302 \\
\hline E2 & 542 & 100 & 100 & Meyerozyma guilliermondii & JN391347 \\
\hline
\end{tabular}

${ }^{1}$ All amplicons were sequenced at both forward and reverse orientations; the query fragments presented correspond to the longest sequence of the two ( $f w d$ for isolates $\mathrm{C}$ and $\mathrm{A} 1$; $r e v$ for $\mathrm{H} 1, \mathrm{H} 2$, and $\mathrm{E} 2$ ). ${ }^{2} \mathrm{E}$-values were equal to zero for $\mathrm{H} 1, \mathrm{H} 2$, and $\mathrm{E} 2$; to $2 \mathrm{e}-166$ for $\mathrm{C}$, and to $1 \mathrm{e}-179$ for A1. ${ }^{3}$ Accession No. corresponds to the descriptive sequences of the taxa indicated in the previous column.

\section{DISCUSSION}

Considering the overall characteristics of the anthropic activity of biodiesel production, large amounts of crude glycerol are generated as waste in this process (Johnson and Taconi, 2007; da Silva et al., 2009). The biotechnological use of microorganisms capable of biodegrading/bioconverting this residue has been the major approach proposed for handling this issue in an economic and environment-friendly manner (Pagliaro et al., 2007; Dobson et al., 2012). The identification of new microbe strains with advantageous features in metabolizing crude glycerol is a requirement, and the tendency in studies of this nature is to seek novel isolates exactly in those environments enriched with the same target substrate (e.g., Maciel et al., 2007; Franciscon et al., 2009). In the present work, we sought an alternative approach for the identification and isolation of microbial activity for consumption of crude glycerol, which was based upon an expectedly large functional biodiversity of soils from the Atlantic Rainforest.

Increased biological activity in soil microcosms enriched with $8 \%$ crude glycerol (Figure 1) suggests that there was microbial growth in the Atlantic Rainforest soil. The crude glycerol, even being exogenous to this habitat and containing various other compounds from the oil transesterification process for biodiesel production (Johnson and Taconi, 2007), seems to have been used as carbon source for microbial metabolism. The oscillations observed in the $\mathrm{CO}_{2}$ emissions over the experimental period may have represented the temporal variation of metabolic adjustments likely required for the microbial bioconversion of crude glycerol. Such behavior may have been due to the fact that, in general, microbial consortia are related to the degradation of exogenous or xenobiotic substances, in which each microorganism performs distinct but synergistic enzymatic activities in a given environmental condition (Gallego et al., 2007). The hypothesis that the consumption of crude glycerol occurs by preexisting microorganisms in Atlantic Rainforest soil is further supported by the observation that, in the control treatment (only with mineral medium added), only a basal production of $\mathrm{CO}_{2}$ was noticed until the 55th day of analysis, with a sharp decline thereafter. This suggests just a minimal biological activity, due to the absence of a carbon source. These data indicate, therefore, that the existing biodiversity of the Atlantic Rainforest soil can be exploited biotechnologically in the biodiesel production context, if crude glycerol-converting microbes can be isolated and cultured in vitro. 
On the basis of these results, we attempted to isolate microorganisms in vitro, from culture medium containing crude glycerol as the carbon source. Such a simple approach indeed allowed the isolation of microbes from Atlantic Rainforest soil with distinct morphological characteristics. This indicated the existence of in vitro-cultivable bacteria and yeasts in this ecosystem, which thereby may have the potential for biotechnological applications in the degradation of residues from biodiesel production. A simple visual inspection and selection of morphologically distinct colonies were effective in capturing at least part of the microbial diversity of interest, demonstrating the potential to be a practical, relatively fast and less expensive technique for screening environmental samples for given purposes. Confirmation of the presence of bacteria and yeast among the isolates was relevant, since these are two important groups from the biotechnological viewpoint (e.g., Papanikolaou et al., 2002; Dharmadi et al., 2006). Interestingly, the presence of bands of slightly different sizes after amplification with the universal primers for yeast (Figure 2) suggests that possible variants of the species identified in databases, or even new species, may have been isolated in this work. As discussed below, this possibility was strengthened by the results of alignment with GenBank sequences (Table 2). Future research aiming at a detailed identification of these isolates is certainly warranted.

A statistical analysis of the OD values at time points along a given growth curve was effective to assess and detect differences between the behavior patterns of isolates cultivated in crude glycerol-containing medium. A comparison of microbial growth suggests important differences related to the respective metabolic behavior of these isolates in terms of bioconversion of this residue. For example, while the A1 and E2 yeasts demonstrated earlier adaptation to the medium, but with cellular biomass stabilizing at lower levels, the opposite occurred with the two bacteria $\mathrm{C}$ and $\mathrm{H} 1$, whose adaptation in culture was delayed, but higher levels of biomass were achieved (Table 1). Such an availability of different patterns of growth response can be useful in different circumstances, mainly for the optimization of fermentation processes to obtain products of biotechnological interest related to crude glycerol conversion. For instance, in time-sensitive applications, when a rapid response to the substrate is a required factor, A1 and E2 yeasts are indicated. On the other hand, when a given technical application requires higher biomass accumulation, $\mathrm{C}$ and $\mathrm{H} 1$ bacteria would be more appropriate.

The two inflections in the growth curve observed for $\mathrm{H} 2$ (Table 1) may indicate different forms of glycerol use, or the metabolism of other compounds existing in the residue. The characteristics observed for the five growth profiles may also have been a consequence of isolate-specific responses to the presence of other compounds in the crude glycerol, such as sodium methoxide (a catalyst of the oil transesterification process) and some fatty acid and alcohol residues (Thompson and He, 2006; Johnson and Taconi, 2007). These substances can either serve as alternative carbon sources or activators/inhibitors of enzymes that are important to the overall microbial metabolism. The implications of these residual components of crude glycerol have been studied for some algal and bacterial species of biotechnological interest (Chiu et al., 2006; Easterling et al., 2009; Liang et al., 2010). In this work, it is suggested that the presence of these residues may also be related to the different patterns of growth and biomass accumulation as a function of time for these microorganisms. The metabolic specificities found for the isolates of this study can be used individually or combined into microbial consortia that can be applied in industry for the degradation of these wastes from the biodiesel production (Gallego et al., 2007; Jensen, 2013). 
The microorganisms isolated and identified in this study provide a first glance at the potential diversity that make up the soil microbiota of the Atlantic Rainforest. Considering the domain bacteria, it was no surprise to find isolates of the Pseudomonas and Bacillus genera, since their various species are widely recognized for metabolic versatility and ability to withstand the most extreme environments, which is why they are found in so many different ecosystems; furthermore, these bacterial genera are widely studied for a variety of anthropogenic purposes (Raaijmakers et al., 2010). Some species of Pseudomonas, Bacillus and Staphylococcus have been reported as being glycerol bioconverters (da Silva et al., 2009; Yang et al., 2012), which may help explain their ability to handle contaminants in crude glycerol. In this study, it is speculated that the H1 sequence that lined up with Pseudomonas citronellolis (Table 2) may represent a variant of this species, or even a new species of this genus, because the 18 extra nucleotides found within the alignment region were not identified in any of the 16S rRNA sequences deposited in GenBank thus far (data not shown). The H2 isolate aligned strongly with an accession of Bacillus megaterium, described as a mostly aerobic spore-forming bacterium, found in a wide variety of ecological niches and capable of growing in an array of carbon sources, which has been used for more than 50 years in the protein-producing industry (Vary et al., 2007). This species has been studied for industrial fermentation based on crude glycerol from biodiesel production as the substrate (Posada et al., 2011). Finally, Staphylococcus was another bacterial genus found in this study, which comprises not only pathogenic species, but also various others described in different contexts, including those that are glycerol degraders (Yang et al., 2012). The ability to degrade residues from the textile industry made up of dyes containing an aromatic azo group has been recently reported for a facultative aerobic isolate of the Staphylococcus arlettae species (Franciscon et al., 2009). The ability of our $S$. arlettae $\mathrm{C}$ isolate to convert crude glycerol seems to be a new feature of biotechnological interest for members of this species.

Yeasts are widely known for their diversity and variability and, hence, extensively studied with regard to various biotechnological applications, including degradation of glycerol (da Silva et al., 2009). Our yeast isolates aligned with maximal identity to accessions of Trichosporon moniliiforme and Meyerozyma (ex Pichia) guilliermondii species (Table 2). T. moniliiforme has been isolated from several soil and water samples, including mangrove sediments, showing ability for bioremediation of xenobiotics (Luo et al., 2012). Antifungal activity of industrial interest for the production of bread has been reported for strains of $M$. guilliermondii (Coda et al., 2013), as well as biological control of fungal diseases during the post-harvest of important agricultural crops (Janisiewicz and Korsten, 2002). We suggest that the yeast isolates from this work may be further studied regarding the possibility of accumulating other characteristics of biotechnological interest, beyond the observed consumption of crude glycerol.

In conclusion, this study demonstrated the feasibility of bioprospecting microorganisms, capable of converting anthropically-generated compounds, within very biodiverse ecosystems (such as Atlantic Rainforest soil) that has not had previous contact with the target substrate in its biological history. Furthermore, it was shown that this procedure can be performed using efficient and low-cost methods, such as Bartha respirometry, in vitro culture and analysis of growth profiles by optical densities. Further characterization of these isolates is currently underway for a more in-depth investigation of their potential for biotechnological use. We hope the information and methodological scheme of this study are not only applicable to handling crude glycerol residues from biodiesel production but also useful in similar bioprospecting or bioremediating systems dealing with the processing of by-products from industrial activities. 


\section{ACKNOWLEDGMENTS}

Research supported by CNPq and UESC. E.A.A. Duarte was awarded a doctoral fellowship from CNPq. This article is dedicated to Prof. Dr. Júlio Cezar de Mattos Cascardo, in memoriam, for being the intellectual mentor and supporter of this line of investigation at UESC. The authors are grateful to Dr. João Carlos Teixeira Dias (DCB/UESC) for insightful comments and suggestions in the early stages of the research.

\section{REFERENCES}

ABNT (Associação Brasileira de Normas Técnicas) (1999). NBR 14283 Resíduos em Solo: Determinação da Biodegradação pelo Método Respirométrico. ABNT, Rio de Janeiro.

Arnold AE, Maynard Z, Gilbert GS, Coley PD, et al. (2002). Are tropical fungal endophytes hyperdiverse? Ecol. Lett. 3: 267-274.

Ashby RD, Solaiman DKY and Strahan GD (2011). Eficient utilization of crude glycerol as fermentation substrate in the synthesis of poly(3-hydroxybutyrate) biopolymers. J. Am. Oil Chem. Soc. 88: 949-959.

Bartha R and Pramer D (1965). Features of flask and method for measurement the persistence and biological effects of pesticides in soil. Soil Sci. 100: 68-70.

Chiu CW, Dasari MA, Sutterlin WR and Suppes GJ (2006). Removal of residual catalyst from simulated biodiesel's crude glycerol for glycerol hydrogenolysis to propylene glycol. Ind. Eng. Chem. Res. 45: 791-795.

Coda R, Rizzello CG, Di Cagno R, Trani A, et al. (2013). Antifungal activity of Meyerozyma guilliermondii: identification of active compounds synthesized during dough fermentation and their effect on long-term storage of wheat bread. Food Microbiol. 33: 243-251.

da Silva GP, Mack M and Contiero J (2009). Glycerol: a promising and abundant carbon source for industrial microbiology. Biotechnol. Adv. 27: 30-39.

Dharmadi Y, Murarka A and Gonzalez R (2006). Anaerobic fermentation of glycerol by Escherichia coli: a new platform for metabolic engineering. Biotechnol. Bioeng. 94: 821-829.

Dobson R, Gray V and Rumbold K (2012). Microbial utilization of crude glycerol for the production of value-added products. J. Ind. Microbiol. Biotechnol. 39: 217-226.

Easterling ER, French WT, Hernandez R and Licha M (2009). The effect of glycerol as a sole and secondary substrate on the growth and fatty acid composition of Rhodotorula glutinis. Bioresour. Technol. 100: 356-361.

Ferreira DF (2011). Sisvar: a computer statistical analysis system. Cienc. Agrotec. 35: 1039-1042.

Franciscon E, Zille A, Guimaro FD, de Menezes CR, et al. (2009). Biodegradation of textile azo dyes by a facultative Staphylococcus arlettae strain VN-11 using a sequential microaerophilic/aerobic process. Int. Biodeter. Biodeg. 63: 280-288.

Gallego JL, Garcia-Martinez MJ, Llamas JF, Belloch C, et al. (2007). Biodegradation of oil tank bottom sludge using microbial consortia. Biodegradation 18: 269-281.

Gungormusler M, Gonen C and Azbar N (2011). 1,3-Propanediol production potential by a locally isolated strain of Klebsiella pneumoniae in comparison to Clostridium beijerinckii NRRL B593 from waste glycerol. J. Polym. Environ. 19: 812-817.

Hanada RE, Pomella AW, Costa HS, Bezerra JL, et al. (2010). Endophytic fungal diversity in Theobroma cacao (cacao) and T. grandiflorum (cupuaçu) trees and their potential for growth promotion and biocontrol of black-pod disease. Fungal Biol. 114: 901-910.

Janisiewicz WJ and Korsten L (2002). Biological control of postharvest diseases of fruits. Annu. Rev. Phytopathol. 40: 411-441.

Johnson DT and Taconi KA (2007). The glycerin glut: options for the value-added conversion of crude glycerol resulting from biodiesel production. Environ. Prog. 26: 338-348.

Lane DJ (1991). 16S/23S rRNA Sequencing. In: Nucleic Acid Techniques in Bacterial Systematics (Stackebrandt E and Goodfellow M, eds.). Wiley Press, Chichester, 130-141.

Liang Y, Sarkany N, Cui Y and Blackburn JW (2010). Batch stage study of lipid production from crude glycerol derived from yellow grease or animal fats through microalgal fermentation. Bioresour. Technol. 101: 6745-6750.

Luo ZH, Pang KL, Wu YR, Gu JD, et al. (2012). Degradation of phthalate esters by Fusarium sp. DMT-5-3 and Trichosporon sp. DMI-5-1 isolated from mangrove sediments. Prog. Mol. Subcell. Biol. 53: 299-328.

Maciel BM, Dias JC, Dos Santos AC, Filho RC, et al. (2007). Microbial surfactant activities from a petrochemical 
landfarm in a humid tropical region of Brazil. Can. J. Microbiol. 53: 937-943.

Marin JA, Hernandez T and Garcia C (2005). Bioremediation of oil refinery sludge by landfarming in semiarid conditions: influence on soil microbial activity. Environ. Res. 98: 185-195.

Mello GSL, Morita DM, Manfredini S and Rivera ING (2007). Viabilidade da aplicação do método respirométrico de Bartha para determinação da biodegradação de poluentes ou resíduos em latossolos. Eng. Sanit. Ambient. 12: 71-78.

Milić JS, Beškoski VP, Ilić MV, Ali SAM, et al. (2009). Bioremediation of soil heavily contaminated with crude oil and its products: composition of the microbial consortium. J. Serb. Chem. Soc. 74: 455-460.

Min YN, Yan F, Liu FZ, Coto C, et al. (2010). Glycerine a new energy source for poultry. Int. J. Poult. Sci. 9: 1-4.

Mu Y, Xiu ZL and Zhang DJ (2008). A combined bioprocess of biodiesel production by lipase with microbial production of 1,3-propanediol by Klebsiella pneumoniae. Biochem. Eng. J. 40: 537-541.

Myers N, Mittermeier RA, Mittermeier CG, da Fonseca GA, et al. (2000). Biodiversity hotspots for conservation priorities. Nature 403: 853-858.

O’Donnell K (1993). Fusarium and its Near Relatives. In: The Fungal Holomorph: Mitotic, Meiotic and Pleomorphic Speciation in Fungal Systematics (Reynolds DR and Taylor JW, eds.). CAB International, Wallingford, UK, 225-233.

Pagliaro M, Ciriminna R, Kimura H, Rossi M, et al. (2007). From glycerol to value-added products. Angew. Chem. Int. Ed. Engl. 46: 4434-4440.

Papanikolaou S, Muniglia L, Chevalot I, Aggelis G, et al. (2002). Yarrowia lipolytica as a potential producer of citric acid from raw glycerol. J. Appl. Microbiol. 92: 737-744.

Posada JA, Higuita JC and Cardona CA (2011). Optimization on the Use of Crude Glycerol from the Biodiesel Production to Obtain Poly-3-Hydroxybutyrate. In: Proceedings of World Renewable Energy Congress, Sweden (Moshfegh B, ed.). Linköping Electronic Conference Proceedings, 57, 327-334.

Raaijmakers JM, De Bruijn I, Nybroe O and Ongena M (2010). Natural functions of lipopeptides from Bacillus and Pseudomonas: more than surfactants and antibiotics. FEMS Microbiol. Rev. 34: 1037-1062.

Rymowicz W, Fatykhova AR, Kamzolova SV, Rywinska A, et al. (2010). Citric acid production from glycerol-containing waste of biodiesel industry by Yarrowia lipolytica in batch, repeated batch, and cell recycle regimes. Appl. Microbiol. Biotechnol. 87: 971-979.

Thompson JC and He BB (2006). Characterization of crude glycerol from biodiesel production from multiple feedstocks. Appl. Eng. Agric. 22: 261-265.

Varrone C, Fiocchetti F, Giussani B, Izzo A, et al. (2012). Bio-Conversion of Biodiesel-Derived Glycerol into Hydrogen and Ethanol: Beyond Second-Generation Biofuels. In: Proceedings of 20th European Biomass Conference \& Exhibition 2012, Milan.

Vary PS, Biedendieck R, Fuerch T, Meinhardt F, et al. (2007). Bacillus megaterium - from simple soil bacterium to industrial protein production host. Appl. Microbiol. Biotechnol. 76: 957-967.

Yang F, Hanna MA and Sun R (2012). Value-added uses for crude glycerol - a byproduct of biodiesel production. Biotechnol. Biofuels 5: 13.

Yazdani SS and Gonzalez R (2007). Anaerobic fermentation of glycerol: a path to economic viability for the biofuels industry. Curr. Opin. Biotechnol. 18: 213-219. 